University of Warwick institutional repository: http://go.warwick.ac.uk/wrap This paper is made available online in accordance with publisher policies. Please scroll down to view the document itself. Please refer to the repository record for this item and our policy information available from the repository home page for further information.

To see the final version of this paper please visit the publisher's website. Access to the published version may require a subscription.

Author(s): H Sandhu, J Dale, N Stallard, R Crouch and E Glucksman Article Title: Emergency nurse practitioners and doctors consulting with patients in an emergency department: a comparison of communication skills and satisfaction

Year of publication: 2009

Link to published version: http://dx.doi.org/10.1136/emj.2008.058917

Publisher statement: None 
EMJ

\section{Emergency nurse practitioners and doctors consulting with patients in an emergency department: a comparison of communication skills and satisfaction}

H Sandhu, J Dale, N Stallard, R Crouch and E Glucksman

Emerg. Med. J. 2009;26;400-404

doi:10.1136/emj.2008.058917

Updated information and services can be found at:

http://emj.bmj.com/cgi/content/full/26/6/400

\section{These include:}

References This article cites 24 articles, 5 of which can be accessed free at: http://emj.bmj.com/cgi/content/full/26/6/400\#BIBL

Rapid responses You can respond to this article at: http://emj.bmj.com/cgi/eletter-submit/26/6/400

Email alerting Receive free email alerts when new articles cite this article - sign up in the box at service the top right corner of the article

Topic collections Articles on similar topics can be found in the following collections

Patients (1886 articles)

Notes

To order reprints of this article go to:

http://journals.bmj.com/cgi/reprintform

To subscribe to Emergency Medicine Journal go to:

http://journals.bmj.com/subscriptions/ 


\title{
Emergency nurse practitioners and doctors consulting with patients in an emergency department: a comparison of communication skills and satisfaction
}

\author{
H Sandhu, ${ }^{1}$ J Dale, ${ }^{1}$ N Stallard, ${ }^{1}$ R Crouch, ${ }^{2}$ E Glucksman ${ }^{3}$
}

\begin{abstract}
${ }^{1}$ Health Sciences Research Institute, Warwick Medical School, University of Warwick, Coventry, UK; ${ }^{2}$ Emergency Department, Southampton University Hospitals NHS Trust, Southampton, UK; ${ }^{3}$ King's College Hospital NHS Foundation Trust, London, UK
\end{abstract}

Correspondence to: Dr H Sandhu, Health Sciences Research Institute, Warwick Medical School, University of Warwick, Coventry CV4 7AL, UK; harbinder.k.sandhu@ warwick.ac.uk

Accepted 9 October 2008

\begin{abstract}
Background: Emergency nurse practitioners (ENPs) play an increasingly important role in UK emergency departments (EDs), but there is limited evidence about how this affects patient care and outcome. A study was undertaken to compare the content of, and satisfaction with, consultations made with patients presenting with problems of low acuity to an ED.
\end{abstract}

Methods: Patients presenting with "primary care" problems were allocated to senior house officers (SHOs, $n=10)$, specialist registrars/staff grades $(n=7)$, sessionally-employed general practitioners (GPs, $n=12$ ) or ENPs $(n=6)$ randomly rostered to work in a consulting room that had a wall-mounted video camera. At the end of each consultation the doctor/ENP and the patient were asked to complete the Physician/Patient Satisfaction Questionnaire. A stratified sample of videotaped consultations $(n=296)$ was analysed in depth using the Roter Interaction Analysis System. The main outcome measures were length of consultation; numbers of utterances of doctor/ENP and patient talk related to building a relationship, data gathering, activating/partnering, and patient education/counselling; doctor/ENP and patient consultation satisfaction scores.

Results: ENPs and GPs focused more on patient education and counselling about the medical condition or therapeutic regimen than did ED doctors. There were no significant differences in consultation length. ENPs had higher levels of overall self-satisfaction with their consultations than ED doctors. Patient satisfaction with how actively they participated in the consultation was significantly associated with the amount of talk relating to building a relationship and activating and partnering, and patient satisfaction with information giving in the consultation was significantly associated with the amount of talk relating to building a relationship.

Conclusion: These findings suggest differences between ENP and ED doctor consultations which are associated with some aspects of patient satisfaction. In contrast to previous reports, consultation length was not greater for ENPs than for doctors. There is a need for further research to test the generalisability of these findings and their impact on clinical outcome.

In recent years there has been a substantial growth in the numbers of emergency nurse practitioners (ENPs) employed in UK emergency departments (EDs), in part reflecting the government's emergency care reform programme. ${ }^{1}$ While there is some evidence that the employment of ENPs may lead to higher patient satisfaction, improved resource use and a more holistic approach to patient care, ${ }^{2-5}$ very little is known about the process of ENP-patient communication, ${ }^{67}$ how this compares with doctorpatient communication and how this affects patient outcome.

Communication skills fundamentally influence the content and outcome of the consultation. ${ }^{8} \mathrm{We}$ recently described the shift in physician consultation style that occurred between 1990 and 2005,9 comparing senior house officers (SHOs), specialist registrars/staff grades and general practitioners (GPs) working in the same inner city ED during both periods. Compared with 1990, in 2005 SHOs and specialist registrars/staff grades showed greater levels of patient-centred communication by placing, for example, more emphasis on building a relationship with the patient and encouraging patient participation in the consultation. There were differences between the hospital doctors and GPs, with the latter placing greater emphasis on counselling and educating the patient by giving more information related to the medical condition.

The aim of the current study was to carry out an in-depth analysis of consultations made by ENPs and to compare these to those of ED doctors and GPs. The specific objectives were to compare (1) consultation length and content; (2) patient satisfaction with the consultation; and (3) clinician satisfaction with the consultation. Satisfaction scores were included to explore associations with the content of the consultation process. ${ }^{10}$ The data included some that has been reported previously. ${ }^{9}$

\section{METHODS}

The full method of patient recruitment and consultation data collection has already been reported, ${ }^{9}$ the key elements of which are described below.

\section{Setting}

The study was set in a busy inner city ED serving a socially-deprived multi-ethnic population and an annual total attendance rate of 117000 in 2005. A consulting room was designated to provide a controlled environment for the consultations. A wall-mounted video camera with a wide-angle lens provided a view of the doctor/ENP and patient.

\section{Study participants}

During sampled $3 \mathrm{~h}$ sessions, all patients (in the case of children, their parent/guardian) who met the study's inclusion criteria were approached 
sequentially by a research assistant. Patients assessed by triage nurses as attending with "primary care problems" (defined as self-referred, with symptoms of a minor type and unlikely to be in need of immediate resuscitation, urgent care or hospital admission) were eligible for inclusion, while those who were unable to give informed consent because of communication or language difficulties or confused mental state were excluded. Eligible patients were offered an explanation of the study, an information sheet and consented to participate.

Doctors and ENPs who routinely saw ambulant patients in the ED were invited to participate. Consultants could not be included for logistic reasons. Weekly rosters allowed allocation of a named clinician to each $3 \mathrm{~h}$ sampled session with the intention that all participants would have at least one $3 \mathrm{~h}$ morning session, one afternoon, one evening and one weekend session included in the sample. Consultations were recorded over a 4-month period from May to August 2005, with the intention of including as many doctor/ENP consultations as possible across different times of the day, evening and all days of the week.

Of the total number of videotaped consultations, 10 were randomly selected and stratified by patient gender (male/ female), patient age (adult/child) and condition (injury/noninjury) for each participating doctor and ENP. This was to minimise the likelihood of observer effects as the clinicians were unaware of which consultations were going to be included in the analysis.

\section{Satisfaction measure}

The Physician and Patient Satisfaction Questionnaire (PSQ) completed after the consultation was chosen as a measure of quality of care that has been validated and takes a few minutes to complete. ${ }^{11}$ It consists of five items measuring involvement in the consultation, information given and received, emotional support given and received, and the quality of the overall interaction. To encourage ease of completion, it was adapted to give each item a Likert scale rated on a scale of 1 (not at all satisfied) to 10 (extremely satisfied).

Consultations were coded using the Roter Interaction Analysis System (RIAS). This enables systematic analysis of verbal utterances ("the smallest discriminable speech segment to which a classification may be assigned" ${ }^{12}$ and has been validated with nurse-patient interactions. ${ }^{13-15}$ Utterances are grouped to produce four main categories: patient education and counselling; data gathering; building a relationship; and activating and partnering. ${ }^{16}$

Three researchers were trained to use the coding system and their inter-rater reliability was tested during the coding process. The intraclass correlations were 0.70 (range for individual coding categories $0.42-0.98 ; 45$ double-coded) and 0.81 (range 0.51-0.96; 18 consultations double-coded), showing good reliability. ${ }^{17}$ Although coders were not blind to whether the clinician was a consulting doctor or ENP (due to the ENPs wearing a distinguishable uniform), they were blind to the grade and status of the consulting doctor. Coders were also unaware of the research question.

\section{Statistical analysis}

Consultation length and the four RIAS summary scores were transformed to ensure normality and compared for the different clinician groups using a random effects model to allow for correlations between results for different consultations performed by the same clinician. In addition to the random clinician effect, the model included terms to adjust for the gender of clinician and patient, whether the patient was a child or an adult and whether or not the purpose of the consultation was an injury.

Satisfaction ratings were compared using Kruskal-Wallis nonparametric analysis of variance. The satisfaction ratings were also dichotomised (1-7 vs 8-10 for clinicians' ratings and 1-9 vs 10 for patients' ratings) and analysed using a multilevel logistic regression model.

\section{RESULTS}

\section{Subjects and participation rates}

Of 44 doctors and ENPs invited to participate, 35 (80\%) consented, comprising 10/13 SHOs, 7/11 specialist registrars/ staff grades, 12/14 GPs and all 6 ENPs. Reasons for nonparticipation included annual leave, sickness absence and study leave, as well as an unwillingness to be videotaped. Fourteen doctors (48\%) and five ENPs (83\%) each recorded fewer than 10 consultations, and hence all their consultations were included in the study. Overall, 22 (62.9\%) of the recruited doctors and nurses were male. There were some differences in the gender mix of each group: 8 GPs (66.6\%), 5 SHOs (50\%), all specialist registrars/staff grades (100\%) and 2 ENPs (33.3\%) were male.

In all, 349 out of 462 patients (75.5\%) approached consented to have their consultation video-recorded. The remainder included $6.7 \%$ who spoke very little or no English, preventing informed consent. Of the 349 consultations, 296 (84.8\%) were sampled for coding, comprising 103 consultations with GPs, 87 with SHOs, 60 with specialist registrar/staff grades and 46 with ENPs (table 1). ENPs had a greater proportion of injury cases than the other groups and GPs had a greater proportion of paediatric consultations. Completion of the PSQ produced a high response rate of $96.3 \%$ for patients and $97.3 \%$ for doctors/ ENPs.

Table 1 Characteristics of doctors, emergency nurse practitioners and patients

\begin{tabular}{|c|c|c|c|c|c|c|}
\hline \multirow[b]{3}{*}{ Consulting clinician } & \multicolumn{6}{|c|}{ Characteristics of patients } \\
\hline & \multicolumn{2}{|l|}{ Gender } & \multicolumn{2}{|l|}{ Age } & \multicolumn{2}{|c|}{ Presenting problem } \\
\hline & Male & Female & Adult & Child & Injury & Non-injury \\
\hline Senior house officer & $42(48.3 \%)$ & $45(51.7 \%)$ & $80(92.0 \%)$ & $7(8.0 \%)$ & $8(9.2 \%)$ & $79(90.8 \%)$ \\
\hline $\begin{array}{l}\text { Specialist registrar/ } \\
\text { staff grade }\end{array}$ & $34(56.7 \%)$ & $26(43.3 \%)$ & $51(85.0 \%)$ & $9(15.0 \%)$ & $10(16.7 \%)$ & $50(83.3 \%)$ \\
\hline Total & $150(50.7 \%)$ & $146(49.3 \%)$ & $225(76.0 \%)$ & $71(24.0 \%)$ & $72(24.3 \%)$ & $224(75.7 \%)$ \\
\hline
\end{tabular}


Table 2 Consultation length (adjusted means with 95\% confidence intervals) for different categories of patients and consulting clinician

\begin{tabular}{lll}
\hline & $\begin{array}{l}\text { Adjusted mean } \\
\text { (95\% CI) }\end{array}$ & $\begin{array}{l}\text { Adjusted } \\
\text { p value }\end{array}$ \\
\hline Adult & $699(621$ to 777$)$ & 0.0153 \\
Child & $573(461$ to 685$)$ & \\
Injury & $580(468$ to 691$)$ & 0.0460 \\
Non-injury & $693(608$ to 777$)$ & \\
General practitioner & $593(467$ to 718$)$ & 0.7178 \\
Senior house officer & $670(521$ to 818$)$ & \\
Specialist registrar/staff grade & $691(511$ to 870$)$ & \\
Emergency nurse practitioner & $592(407$ to 776$)$ & \\
\hline
\end{tabular}

\section{Consultation length}

The mean (SD) consultation length was 692.7 (377.2) s. Consultations were significantly shorter for children than for adults, and for patients with an injury than for non-injury patients (table 2). Although the mean consultation length was less for GPs and ENPs than for SHOs and staff grades/specialist grades, this difference was not statistically significant.

\section{Clinician communication}

Table 3 shows the geometric mean number of utterances (adjusted for type of clinician and other covariates allowing for the individual clinician effects) for the main communication outcomes.

The number of utterances related to "data gathering", "building a relationship" and "activating and partnering" was not found to differ significantly between the three types of doctors and ENPs $(p=0.378, p=0.368$ and $p=0.703$, respectively). However, analysis of individual RIAS variables using Kruskal-Wallis ANOVA and Mann-Whitney $U$ tests revealed some differences. For example, compared with ENPs (mean 4.57, range 0-23), SHOs asked more open questions related to the medical condition (mean 9.53, range 0-34; $<<0.001$ ), as did specialist registrars/staff grades (mean 8.38, range 1-31; $\mathrm{p}<0.001$ ). ENPs, however, asked more open questions related to the patient's current therapeutic regimen (mean 2.48, range $0-7$ ) than SHOs (mean 1.80, range 0-8; $p<0.05$ ), specialist registrars/staff (mean 1.33, range $0-4 ; \mathrm{p}<0.001$ ) and GPs (mean 0.99 , range $0-5 ; \mathrm{p}<0.001)$.

SHOs gave significantly more agreements and statements of understanding during the consultation (mean 28.79, range 2-85) than ENPs (mean 22.2, range 5-70; $\mathrm{p}<0.05$ ). Registrars gave significantly more disapproval statements, which included criticism or disagreement with information, ideas or opinions given by the patient during the consultation (mean 2.60, range 0-23) than ENPs (mean 0.41, range 0-3; p <0.05).

For "activating and partnering" talk, SHO consultations included more utterances that checked for patient understanding (mean 21.90, range 2-61) than ENPs (mean 13.1, range $0-40 ; \mathrm{p}<0.001$ ) or asked for the patient's opinion (mean 2.14, range 0-14) than ENPs (mean 1.04, range 0-5; $\mathrm{p}<0.001$ ). Specialist registrar/staff grades' consultations included more utterances that asked about the patient's understanding (mean 9.65, range $0-32$ ) than those of ENPs (mean 5.39, range 0-32; $\mathrm{p}<0.001$ ).

As shown in table 3 , significant differences were observed between the different types of doctors and ENPs in the number of utterances related to "patient education and counselling". The number of utterances related to this variable was significantly greater for the GPs (mean 38.1, 95\% CI 25.2 to 57.5) and ENPs (mean 33.2, 95\% CI 17.3 to 63.8) than for SHOs (mean 13.6, 95\% CI 8.6 to 21.4); specialist registrars/staff grades (mean 25.3, 95\% CI 14.3 to 44.7) did not differ significantly from any other group. Mann-Whitney $U$ tests showed that ENPs gave significantly more information $(p<0.05)$ related to the therapeutic regimen (mean 12.04, range 0-41) than SHOs (mean 9.22, range $0-34$ ).

\section{Patient and consulting clinician satisfaction}

Patient satisfaction is given in table 4. A comparison of these scores with the clinician satisfaction scores given in table 5 shows that satisfaction was generally greater for patients, with many patients giving the maximum rating of 10 . SHOs had slightly lower patient satisfaction ratings than other groups in relation to how satisfied patients were with the information they were given and in overall satisfaction scores.

Multilevel logistic regression modelling identified a significant relationship between the maximum satisfaction ratings of 10 for level of active participation and the number of utterances relating to "building a relationship" $(p=0.001)$ and "activating and partnering" ( $p=0.019)$, and between satisfaction ratings of 10 for adequacy of information giving and emotional support and the number of utterances relating to "building a relationship" ( $p=0.05)$. No other significant effects of patient or doctor and ENP gender, injury/non-injury, length of consultation, patient age or summary measures of doctor/ENP communication were found, and adjustment for the number of utterances did not change the significant differences between the different types of clinician in the patients' satisfaction with the adequacy of information given.

As shown in table 5, there were statistically significant differences between the different clinician groups across all of the self-satisfaction scores. GPs tended towards lower levels of self-satisfaction with their consultations than other groups, while ENPs generally had the highest ratings and, for overall satisfaction with the consultation, this difference was statistically significant. Multilevel logistic regression modelling did not indicate any significant relationship between satisfaction ratings of eight or more and patient or doctor gender, injury/ non-injury, length of consultation, patient age or the summary measures of clinician communication described above.

Table 3 Associations between adjusted means (95\% confidence intervals) for the four "doctor talk" outcome variables and the category of consulting healthcare professional

\begin{tabular}{|c|c|c|c|c|c|}
\hline & Adjusted mean $(95 \% \mathrm{CI})$ & Adjusted mean $(95 \% \mathrm{CI})$ & Adjusted mean $(95 \% \mathrm{CI})$ & Adjusted mean (95\% CI) & \\
\hline & General practitioner & Senior house officer & $\begin{array}{l}\text { Specialist registrar/staff } \\
\text { grade }\end{array}$ & $\begin{array}{l}\text { Emergency nurse } \\
\text { practitioner }\end{array}$ & $\begin{array}{l}\text { Adjusted } \\
\text { p value }\end{array}$ \\
\hline Patient education and counselling & $38.1(25.2$ to 57.5$)$ & 13.6 (8.6 to 21.4 ) & $25.3(14.3$ to 44.7$)$ & $33.2(17.3$ to 63.8$)$ & 0.0111 \\
\hline Data gathering & 19.1 (15.4 to 23.7$)$ & $25.3(20.0$ to 32.0$)$ & $22.9(17.0$ to 30.9$)$ & 23.2 (16.8 to 32.0$)$ & 0.3782 \\
\hline Building a relationship & 33.4 (26.6 to 42.0$)$ & $37.4(29.1$ to 48.1$)$ & 47.3 (34.3 to 65.3$)$ & 35.5 (25.2 to 49.8$)$ & 0.3676 \\
\hline Activating and partnering & 44.7 (34.4 to 58.0$)$ & $55.9(41.9$ to 74.5$)$ & 53.5 (37.4 to 76.5$)$ & 49.3 (32.4 to 75.2 ) & 0.7031 \\
\hline
\end{tabular}


Table 4 Comparison of patient satisfaction scores (unadjusted means) for consultations made by different types of clinician

\begin{tabular}{|c|c|c|c|c|c|}
\hline & $\begin{array}{l}\text { General } \\
\text { practitioner }\end{array}$ & $\begin{array}{l}\text { Senior house } \\
\text { officer }\end{array}$ & $\begin{array}{l}\text { Specialist } \\
\text { registrar/staff } \\
\text { grade }\end{array}$ & $\begin{array}{l}\text { Emergency } \\
\text { nurse } \\
\text { practitioner }\end{array}$ & p Value \\
\hline $\begin{array}{l}\text { How well did the doctor/nurse address } \\
\text { your needs? }\end{array}$ & 8.9 & 9.0 & 9.4 & 8.9 & 0.181 \\
\hline $\begin{array}{l}\text { How actively were you involved in } \\
\text { talking and participating in the } \\
\text { consultation? }\end{array}$ & 8.8 & 8.8 & 9.2 & 8.6 & 0.142 \\
\hline $\begin{array}{l}\text { How satisfied are you with the } \\
\text { adequacy of the information you } \\
\text { received from this doctor/nurse? }\end{array}$ & 9.0 & 8.7 & 9.5 & 9.2 & 0.008 \\
\hline $\begin{array}{l}\text { How satisfied were you with the } \\
\text { emotional support you received from } \\
\text { the doctor/nurse? }\end{array}$ & 8.9 & 8.6 & 9.1 & 8.9 & 0.231 \\
\hline $\begin{array}{l}\text { Overall, how satisfied are you with the } \\
\text { consultation? }\end{array}$ & 9.1 & 8.8 & 9.4 & 9.3 & 0.013 \\
\hline
\end{tabular}

\section{DISCUSSION}

This study provides evidence of how the assessment and advice patients receive in an ED may be dependent upon the grade and type of clinician who undertakes the consultation. For example, ENPs were found to focus more of the consultation on providing information to patients and engaged patients more fully in decision-making processes, a finding supported by previous research. ${ }^{18}$ In contrast, $\mathrm{SHOs}$ were more likely to encourage patients to participate in the consultation by checking the patient's understanding and asking for the patient's opinion. Such communication allows patients to express their concerns or expectations and is likely to enhance the overall patient experience. ${ }^{19}{ }^{20}$ Unlike previous research that found that ENPs have longer consultations, ${ }^{21}$ this was not the case in this study.

ENPs, like GPs, appear to place greater emphasis on educating and counselling the patient and give advice about the therapeutic regimen (including discussion about treatment plans) than $\mathrm{SHOs}$ and specialist registrars/staff grade doctors. ${ }^{15} 18$ Information-giving in EDs has been shown to help enable patients to understand their condition and successfully participate in decision making and has also been associated with increased patient satisfaction. ${ }^{22}{ }^{23}$ There was evidence of this association in the current study, with patients who consulted an ENP expressing greater satisfaction with the information and support received in the consultation than those who had consulted with an SHO. This highlights benefits that may ensue from ENP care. ${ }^{524}$
ENPs tended to express higher levels of self-satisfaction with their consultations than did the doctors, particularly in terms of the adequacy of information given to the patient, the emotional support and overall satisfaction level. Research suggests that ENPs find their role rewarding and stimulating and have high levels of overall job satisfaction. ${ }^{25}$ Familiarity and greater experience of practice in an ED may have influenced satisfaction levels, with ENPs often having worked for many more years in emergency care than the doctors in this study. In addition, it might be that $\mathrm{ED}$ doctors derive more satisfaction from attending the more seriously injured or ill patient rather than the ambulant patients included in the cohort studied here.

\section{Methodological considerations}

A full discussion of the methodological issues associated with the study has been described previously. ${ }^{9}$ A major strength is that its data reflect everyday consultations within an $\mathrm{ED}$, in contrast to studies that have investigated consultation skills using simulated patients. Although there may have been an observer effect resulting in some changes in behaviour due to the clinicians being aware that they were being videotaped, the sampling process was adjusted to minimise this effect. However, the applicability of findings is limited by data only having been collected within a single department, and few ENPs and doctors being included. There is a need for a larger scale study with data collection from several departments to test generalisability and to further characterise the differences in consulting style in relation to the quality of care given.

Table 5 Comparison of clinicians' self-satisfaction scores (unadjusted means)

\begin{tabular}{|c|c|c|c|c|c|}
\hline & $\begin{array}{l}\text { General } \\
\text { practitioner }\end{array}$ & $\begin{array}{l}\text { Senior house } \\
\text { officer }\end{array}$ & $\begin{array}{l}\text { Specialist } \\
\text { registrar/staff } \\
\text { grade }\end{array}$ & $\begin{array}{l}\text { Emergency } \\
\text { nurse } \\
\text { practitioner }\end{array}$ & p Value \\
\hline $\begin{array}{l}\text { How well did you address the } \\
\text { needs of this patient? }\end{array}$ & 7.5 & 7.9 & 8.4 & 8.5 & $<0.0001$ \\
\hline $\begin{array}{l}\text { How actively was the patient } \\
\text { involved in talking and } \\
\text { participating in consultation? }\end{array}$ & 7.5 & 8.1 & 8.3 & 8.1 & 0.004 \\
\hline $\begin{array}{l}\text { How satisfied were you with the } \\
\text { adequacy of the information you } \\
\text { gave to this patient? }\end{array}$ & 7.7 & 8.1 & 8.3 & 8.6 & 0.001 \\
\hline $\begin{array}{l}\text { How satisfied were you with the } \\
\text { emotional support you gave to } \\
\text { this patient? }\end{array}$ & 7.6 & 7.3 & 7.7 & 8.4 & 0.002 \\
\hline $\begin{array}{l}\text { Overall, how satisfied are you } \\
\text { with the consultation? }\end{array}$ & 7.5 & 7.8 & 8.1 & 8.6 & 0.0003 \\
\hline
\end{tabular}


Currently there is no educational benchmark for ENPs, with some having in-house training and others completing a full academic programme. ${ }^{26}$ The extent to which educational attainment and consulting styles are associated also warrants study.

\section{CONCLUSION}

Compared with ED doctors, ENPs provide more education and counselling to patients, particularly in relation to the therapeutic regimen. In this respect, their consulting style appeared similar to that of the GPs. However, SHOs encouraged patients to participate in the consultation by checking their understanding more. Although patient satisfaction levels were globally high, patients appeared to be more satisfied with ENP consultations than with $\mathrm{SHO}$ consultations. Future research is needed to investigate the generalisability of these findings and to explore how differences in ED consultation style influence clinical outcome.

Acknowledgements: The authors thank Mr Simon Porsz, Mr Cedric Mascarenhas, Ms Pat Davis and Dr Tunji Lasoye who supported data collection and all the doctors and ENPs who agreed to take part in the study. They are also grateful to all nursing staff involved in identifying patients and to all patients who participated in the study; Dr Susan Larson and Professor Debra Roter for their guidance in using the Roter Interaction Analysis System; and Lynn Tang, Laura Singleton and Vicky Ward for coding the consultations.

Funding: This study was funded by the Burdett Trust for Nursing.

Competing interests: None.

Ethics approval: Ethical approval was given by the local research ethics committee.

\section{REFERENCES}

1. Department of Health. Reforming emergency care: first steps to a new approach. London: Department of Health, 2001. http://www.dh.gov.uk/assetRoot/04/05/88/36/ 04058836.pdf (accessed 2 Mar 2009).

2. Tye CC, Ross F, Kerry SM. Emergency nurse practitioner services in major accident and emergency departments: a United Kingdom postal survey. J Accid Emerg Med 1998; 15:31-4.

3. Sakr M, Angus J, Perrin J, et al. Care of minor injuries by emergency nurse practitioners or junior doctors: a randomised controlled trial. Lancet 1999;354:1321-6.

4. Freij RM, Duffy T, Hackett D, et al. Radiographic interpretation by nurse practitioners in a minor injuries unit. J Accid Emerg Med 1996;13:41-3.
5. Byrne G, Richardson M, Brunsdon J, et al. Patient satisfaction with emergency nurse practitioners in A\&E. J Clin Nurs 2000;9:83-93.

6. Brown SJ. Patient centred communication. Annu Rev Nurs Res 1999;17:84-104.

7. Chang $\mathbf{E}$, Daly J, Hawkins A, et al. An evaluation of the nurse practitioner role in a major rural emergency department. J Adv Nurs 1999;30:260-8.

8. Lussier MT, Richard C. Doctor-patient communication, Introduction to series. Can Fam Physician 2004;50:43-7.

9. Dale J, Sandhu H, Lall R, et al. The patient, the doctor and the emergency department: a cross-sectional study of patient-centeredness in 1990 and 2005. Patient Educ Couns 2008;72:320-9.

10. Suchman AL, Roter D, Green M, et al. Physician satisfaction with primary care office visits. Collaborative study group of the American Academy on Physician and Patient. Med Care 1993;31:1083-92.

11. Zandbelt CL, Smets AM, Oort JF, et al. Satisfaction with the outpatient encounter: a comparison of patients' and physicians' views. J Gen Intern Med 2004;19:1088-95.

12. Roter DL. The Roter Method of Interaction Process Analysis. RIAS Manual, Baltimore, 1991. http://www.rias.org/manual.html (accessed 2 Mar 2009).

13. Kruijver MPI, Kerkstra A, Bensing MJ, et al. Communication skills of nurses during interactions with simulated cancer patients. J Adv Nurs 2001;34:772-9.

14. Caris-Verhallen W, Timmermans L, Van Dulmen S. Observation of nurse-patient interaction in oncology: review of assessment instruments. Patient Educ Couns 2004;54:307-20.

15. Kim EJ. Emergency nurse-patient interaction behaviour. J Korean Acad Nurs 2005;35:1004-13.

16. Roter D, Larson S. The relationship between residents' and attending physicians' communication during primary care visits and illustrative use of the Roter Interaction Analysis System. Health Commun 2001;13:33-48.

17. Bartko JJ, Carpenter WT. On the methods and theory of reliability. J Nerv Ment Dis 1976;163:307-17.

18. Haumueller EM. Nurse-patient communications. Accid Emerg Nurs 1994;2:216-9.

19. Epstein RM, Franks P, Fiscella K, et al. Measuring patient-cantered communication in patient-physician consultations: theoretical and practical issues. Soc Sci Med 2005;61:1516-28.

20. O'Gara PE, Fairhurst W. Therapeutic communication part 2: Strategies that can enhance the quality of the emergency care consultation. Accid Emerg Nurs 2004; 12:201-7.

21. Byrne G, Richardson M, Brunsdon J, et al. An evaluation of the care of patients with minor injuries in emergency settings. Accid Emerg Nurs 2000;8:101-9.

22. Williams S, Weinman J, Dale J. Doctor-patient communication and patient satisfaction: a review. Fam Pract 1998;15:480-92.

23. Krishel S, Baraff LJ. Effect of emergency department information on patient satisfaction. Ann Emerg Med 1993;22:568-72.

24. Cooper AM, Lindsay MG, Kinn S, et al. Evaluating emergency nurse practitioner services: a randomised controlled trial. J Adv Nurs 2002;40:721-30.

25. Brugees K. A dynamic role that improves the service: combining triage and nurse practitioner roles in A\&E. Prof Nurse 1992;7:301-3.

26. Brook S, Crouch R. Doctors and nurses in emergency care: where are the boundaries now? Trauma 2004;6:211-6. 